\title{
The TAPS project
}

\section{6: Difficult to place, long term psychiatric patients: risk factors for failure to resettle long stay patients in community facilities}

\author{
David Dayson, Christopher Gooch, Graham Thornicroft
}

\begin{abstract}
Objective-To identify patients who could not be resettled in the community as part of the closure plans of two psychiatric hospitals and to determine their numbers and risk factors for failure.

Design and setting-Prospective study of the closure of Friern and Claybury psychiatric hospitals.

Patients-The first third (369) of long stay psychiatric patients to be resettled.

Outcome measures-Reasons for patients being readmitted to hospital and not leaving the patients' service needs.

Results $-22-6 \%$ of both hospitals' long stay patients-were not successfully resettled in the community. Eighteen continuing care places per 100000 of catchment area population seem to be required for this group. Patients whose placements were unsuccessful were usually readmitted because of a deterioration of their mental state and aggressive behaviour, both of which persisted and necessitated their continuing stay in hospital, often in a locked ward. Risk factors associated with failure were a high level of psychosis; a diagnosis of paranoid psychosis; incontinence; and being male. But having a social network, especially a large one, seemed to aid successful placement in the community.

Conclusion-Rehabilitation efforts should be focused on the characteristics of these patients that put them at risk of failing to succeed in community placements.
\end{abstract}

\section{Introduction}

The only mental health target in the government's original consultation document on The Health of the Nation was to "realign the resources currently spent on specialist psychiatric services into district based care, thereby allowing many of the remaining 90 large psychiatric hospitals to be closed before the year 2000 ." In the final document this has been replaced by three different targets, ${ }^{2}$ but the intention to develop locally based services remains. An underlying presumption is that it is possible entirely to close a large psychiatric hospital. This paper, however, describes the characteristics of patients whom it has not proved possible to discharge from hospital care using data from a large prospective evaluation of mental hospital closures. ${ }^{3}$

The functions of a psychiatric hospital are diverse. The main overt tasks are to provide refuge and an opportunity for recuperation from the deleterious effects of severe mental illness. ${ }^{5}$ A small group of patients have emerged during the programme to close Friern and Claybury Hospitals who have proved difficult to place outside hospital and who appear to be in continuing need of long term highly supported care. Their existence needs recognising ${ }^{6}$ lest they are passed over in the midst of the economic and humanitarian zeal to close hospitals. Unless the full range of services are reprovided, including intensive long stay nursing and residential homes, the community psychiatry movement risks winning a Cadmean victory.

Fifteen years ago Christie-Brown described the long stay population of Friern Hospital and estimated that $29 \%$ would need continuing hospital care. ${ }^{7} \mathrm{He}$ stated, "More detailed and quantifiable assessments are necessary so that the testing of predictions against outcome can be made more accurate." This paper reports such a study.

\section{Aims of the study}

The study had three aims: (a) to identify patients who were not successfully resettled in the community as part of the reprovision programmes of Friern and Claybury Hospitals; $(b)$ to describe the reasons for readmission, for continuing to remain in hospital, and their service needs, and to identify risk factors for patients becoming "difficult to place" in the community from baseline hospital data; and $(c)$ to estimate how many of the remaining hospital population may in turn become difficult to place and to compare this estimate with the planned number of highly supported places.

\section{Subjects and methods}

This was a substudy within the continuing evaluation of the closure of Friern and Claybury Hospitals. In 1983 North East Thames Regional Health Authority decided to close two out of six of its large psychiatric hospitals. The health authority included an evaluation of the closure process, performed by the Team for the Assessment of Psychiatric Services (TAPS). The first patients began leaving in September 1985. In 1991 Claybury Hospital halted its closure because the health authority lacked sufficient capital to continue to fund the scheme. The closure of Friern Hospital, however, continued on course, and the last patients are due to leave in March 1993.

All patients who had been in either hospital for a year or more entered the study and underwent a comprehensive psychiatric and social assessment while still in hospital. Those over 65 with a primary diagnosis of dementia were excluded and are part of a separate study. The 11 schedule assessment, developed by the team, measured: demographic data, physical health, patients' attitudes (patient attitude questionnaire), ${ }^{8}$ psychiatric symptoms (present state examination), social network (social network schedule), ${ }^{10}$ social behaviour (social behaviour schedule), ${ }^{11}$ daily living skills, environmental restrictiveness, homeliness of setting, services received, and work problems. Community follow up studies are reported elsewhere..$^{1213}$

By November 1990 a small group of resettled patients were back in their parent hospitals. These difficult to place patients were defined as resettled patients who had been readmitted to hospital and continued to stay there for at least a further year without any further efforts at resettlement during the 
study period (September 1985-November 1990). The data on these patients were obtained from various sources: case notes (causes of readmission and service use); consultant's opinion (reasons for continuing in hospital); and TAPS hospital assessment schedules (data for a logistic regression analysis to identify risk factors for becoming difficult to place). For each patient these schedules yielded over 500 items of data. These were reduced to summary variables and 30 were selected (table I).

The 30 variables were selected a priori on clinical grounds. Selected variables were also chosen to represent each of the major schedules and were those considered most important within each schedule. Many of the variables used were summary scores derived from the broad range of information collected during interview. Clearly no statistical data reduction was used. Most of the variables not included were either subscales of scores that were used or variables not suitable for quantitative analysis. Most were patient variables but three process variables were includednamely, the parent hospital and the type of community facility categorised in two different ways (staffed group home $v$ all others; public $v$ private $v$ voluntary run homes).

\section{STATISTICAI, METHODS}

Multiple linear logistic regression analysis was used to assess the simultaneous effect of the 30 summary variables (table I) on the risk of a patient becoming difficult to place. The most parsimonious logistic regression model was used to generate relative odds ratios and $95 \%$ confidence limits for each explanatory factor in turn while controlling for the others. To detect any systematic bias we used the final regression model to estimate the number of difficult to place patients and compared this estimate with the true number.

We next estimated how many of the remaining hospital long stay patients might also in turn become difficult to place. To do this we applied the risk factors derived from the resettled patients to each of the

TABLE I-Variables entered into the logistic regression model subdivided according to the TAPS schedule

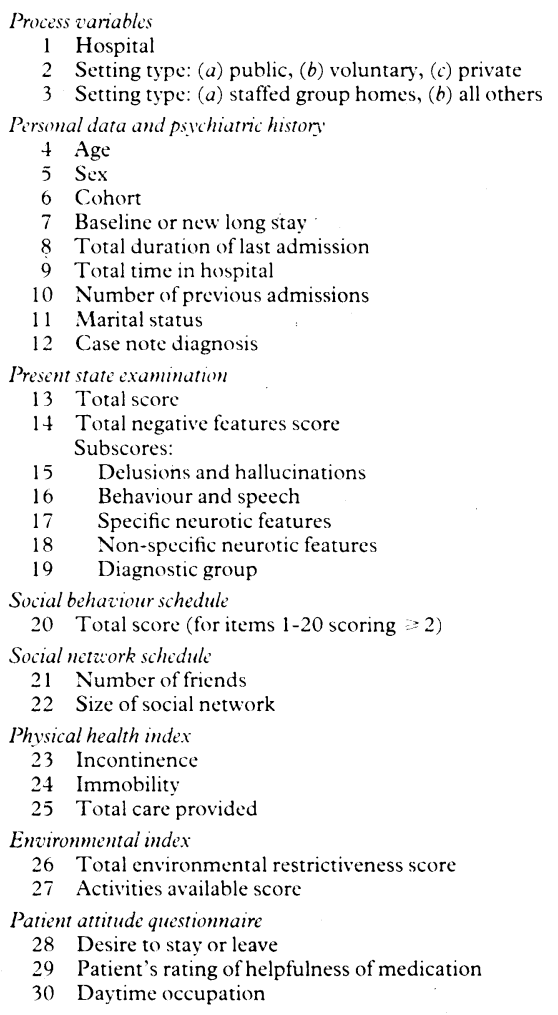

remaining long stay patients in hospital and calculated an individual risk for becoming difficult to place for each one. These probabilities were summed to produce an overall estimate for the likely number of difficult to place patients among those who had yet to be discharged. This statistical estimate was then compared with the actual remaining beds being planned. We recognised, though, that the application of risk factors derived from one population to another which may have a different composition introduces possible inaccuracies.

\section{Results and comment}

CAUSES OF READMISSION AND CONTINUING IN HOŞPITAL

By November 1990, four years and two months into a seven and a half year closure programme, 369 long stay patients had been resettled with another 615 yet to leave. Twenty two $(6 \%)$ had become difficult to place. Four of the difficult to place patients had died while back in hospital, all from natural causes consistent with their old age.

Twelve of the difficult to place patients were readmitted because of aggression or threatening behaviour. In nine patients this behaviour coexisted with a deterioration in their mental state. Five were physically aggressive: one tried to stab his father at the beginning of the research assessment, one repeatedly beat his mother, one was aggressive to his adult fosterers and threatened to kill his social worker, one hit fellow hostel residents, and one slashed a hostel resident with a knife.

Six more patients were readmitted for other reasons: one each for physical deterioration, absconding, and non-payment of rent. Another returned because the hostel could no longer cope with her stealing, begging, prostitution, and drug abuse. Another was arrested for indecent exposure and assault of a female hostel resident, whereupon he was granted bail and readmitted. One patient referred himself back to hospital on release from prison when he had nowhere else to go.

Case note data were missing for one patient and the relevant notes were untraceable for the remainder.

After readmission, case note entries were sporadic, incomplete, and usually in response to a crisis. Therefore to ascertain why the patients remained in hospital we asked each of their consultants this question in writing. We received 16 replies out of a possible 19 , as we did not approach the consultants of three patients who had died some time earlier in hospital. They were free to answer with as much information as they wanted to. Then we sorted the information in each reply into empirical categories of patient characteristics, which were then ranked in order of frequency.

The most often reported causes for remaining in hospital were: intermittent aggressive or threatening behaviour (10 patients), persistent symptoms (10), alcohol or drug use (6), interpersonal behaviour problems (5). The most frequently reported combination was persistent symptoms and intermittent aggression (seven patients).

Antipsychotic medication was increased for nine patients, but clozapine was given to only one patient, despite its indication in schizophrenia resistant to treatment. Only three patients had a full assessment of needs documented as a problem list and none had a documented structured behavioural programme for intermittent aggression. Most were nursed on either intensive rehabilitation wards (seven) or rehabilitation wards (five). A minority remained in other settings: acute admissions ward (two), psychogeriatric ward (two), medium secure unit (one), private secure unit (one). For the remainder the ward type was not clearly documented.

Ten patients needed locked wards and eight were 
TAB1.1 I--Relative odds (and 95\% confidence interials) for readmission aithout discharge in follow up

\begin{tabular}{|c|c|c|}
\hline Variable & $\begin{array}{c}\text { Lnadjusted } \\
\text { relative odds } \\
\left(95^{\circ} \ldots \text { confidence interval }\right)\end{array}$ & $\begin{array}{c}\text { Adjusted logistic } \\
\text { relative odds } \\
\left(95^{\prime \prime} /, \text { confidence interval }\right)\end{array}$ \\
\hline \multicolumn{3}{|l|}{$\begin{array}{l}\text { Delusion and } \\
\text { hallucination score: } \\
(0-13\end{array}$} \\
\hline 214 & $4.36(1.46$ to 13.00$)$ & $10 \cdot 15(2.43$ to $42 \cdot 41)$ \\
\hline \multicolumn{3}{|l|}{$\begin{array}{l}\text { Diagnostic group: } \\
\text { Non-paranoid } \\
\text { psychoses }\end{array}$} \\
\hline $\begin{array}{l}\text { Paranoid } \\
\text { psychoses }\end{array}$ & $3.00(1.03$ to 8.76$)$ & $5.02(1.40$ to 18.09$)$ \\
\hline $\begin{array}{l}\text { Incontinence: } \\
\text { Not incontinent }\end{array}$ & $4.14(1.49+0-11.50)$ & \\
\hline \multicolumn{2}{|l|}{ Sex: } & $4.98(1.56$ to 15.90$)$ \\
\hline $\begin{array}{l}\text { Female } \\
\text { Male }\end{array}$ & $3.61(1.19$ to 10.9$)$ & $2.79(0.85$ to 9.09$)$ \\
\hline \multicolumn{3}{|l|}{ Hospital: } \\
\hline Friern & $2.65(0.95$ to 7.40$)$ & $2.43(0.79$ to 7.45$)$ \\
\hline $\begin{array}{l}\text { Social network: } \\
\text { Non-response } \\
0-8\end{array}$ & $0.37(0.14$ to 1.01$)$ & $0.26(0.08 \text { to } 0.81)^{\circ}$ \\
\hline Size $\geqslant 9$ (median) & $0.21(0.06$ to 0.72$)$ & $0.13(0.03$ to 0.57$)$ \\
\hline
\end{tabular}

maintained in hospital under a compulsory order. Four had two or three changes of ward during their stay as they graduated to wards with higher levels of supervision, thus indicating that they were difficult to place both in the community and within the hospital.

RISK FACTORS FOR BECOMING DIFFICULT TO PLACE

Using linear interactive modelling we compared the 22 difficult to place patients with the remaining resettled patients $(n=347)$ who had stayed out of hospital. The 27 patient variables and three process variables shown in table I were entered into this modelling procedure and table II shows the results.

Patients with large numbers of psychotic symptoms, defined as a score of 14 or more on the present state examination delusions and hallucinations subscore, were 10 times more likely to become difficult to place than those who were less psychotic. Those with either a paranoid psychosis or incontinence were about five times more likely and men three times more likely to become difficult to place. Although Friern Hospital was almost two and a half times more likely to produce community failures than Claybury Hospital, we believe this was solely due to a difference in readmission policy. At Claybury Hospital readmission from community settings was resisted on the grounds that the community facilities had more staff than the wards patients would return to.

In contrast, larger social networks seemed to offer protection from becoming difficult to place. The network size was defined as the number of people the patient had been in contact with over the previous month. Those patients with large networks (greater than the median of nine) had about one seventh of the risk and those with small networks about a quarter of the risk of becoming difficult to place when compared with those who refused to answer the questionnaire, whom we know to be the most asocial group from another study of the social networks of this hospital population.

To detect any systematic bias the final regression model was used to estimate the number of difficult to place patients. The fitted estimate was 20 compared with the true number of 22 . Therefore we conclude that the relative odds for each risk factor were if anything slightly underestimated.

PLANNED VERSUS ESTIMATED NEED

We then applied these risk factors to each of the hospital long stay patients who had yet to leave to produce a statistical estimate of the number of beds that would still be needed. Each remaining patient had his risk calculated and these were summed to produce an overall figure. Thus if closure had continued at Claybury Hospital the residual population $(n=296)$ would have generated $19(6 \%)$ patients who would have become difficult to place, whereas the residual population of Friern Hospital $(n=319)$, which is proceeding with closure, is likely to produce $36(11 \%)$.

Friern Hospital planning department staff made their own independent estimate of the final residual places needed by asking each clinical team for its own figure. Thus, Friern Hospital is planning for 80 long stay places; 34 are designated "special needs," where the patients are not expected to leave, and 46 are intensive rehabilitation places, where patients are expected to leave after long term rehabilitation. Friern Hospital serves a population of 450000 , so this produces an estimate of 18 long stay hospital beds per 100000 of catchment area population. The planned figure of special needs places $(n=34)$ is similar to our statistical estimate of 36 places. The closeness of our statistical estimate to the actual independently planned number of special needs beds validates the risk factors we have identified for the category of difficult to place long term psychiatric patients.

\section{Conclusion}

We have shown that, despite a demonstration programme of hospital closures, a few patients continue to need highly supported places, some of which may need to be in locked facilities. The management of these difficult to place patients should incorporate the following: individual care plans with full identification of needs to produce resident orientated care; behavioural regimens, particularly for intermittent aggression and problem behaviours; and specific targeting of alcohol and illicit drug use.

Three of the five variables associated with being difficult to place may well be remedial. A high level of psychotic symptoms may be reduced by appropriate medication such as clozapine. ${ }^{15}$ Incontinence may respond to a behavioural programme. Asociability may be improved by providing social settings that encourage non-verbal transactions so as to foster relationships." Hence, these risk factors for unsuccessful community placement can be seen as pivotal areas on which to focus the effort of rehabilitation.

1 Department of Health. The Health of the Nation. London: HMSO, 1991 2 Department of Health. The Health of the Nation. London: HMSO, 1992 3 Kendell RE. The future of Britain's mental hospitals. BMF 1989;299:1237-8.

4 Thornicroft G, Bebbington P. Deinstitutionalisation--from hospital closure to service development. Br f Psychiatry 1989;155:739-53.

5 Wing JK. The functions of asylum. Br 7 Psychiatry 1990;157:822-6.

6 Coid JW' "Difficult to place" psychiatric patients. BM7 1991;302:603-4 7 Christie-Brown JRW. A surcey of a long-stay psychiatric population.

8 Thornicroft G, Gooch C, O'Driscoll C, Reda S. The TAPS Project. 9: The Reliability of the Patient Attitude Questionnaire (in press)

9 Wing JK, Cooper JE, Sartorius N. Description and classification of psychiatric Wing JK, Cooper JE, Sartorius N. Description and clas
symptoms. London: Cambridge University Press, 1974.

10 Dunn M, O'Driscoll C, Dayson D, Wills W, Leff J. The TAPS Project 4: An observational study of the social life of long-stay patients. Br $\mathcal{F}$ Psychiatry $1990 ; 157: 842-8$

11 Sturt E, Wykes T. The social behaviour schedule: a validity and reliability study. Br F Psychiatry 1986;148:1-11

12 Dayson $\mathrm{D}$. The TAPS Project. 12: Crime, vagrancy, death and readmission of the long-term mentally ill during their first year of local reprovision. $\operatorname{Br}$ P Psychiatry (suppl) (in press)

13 Anderson J, Dayson D, Wills W, Gooch C, Margolius O, Leff J. The TAPS Project. 13: Prospective one year follow up of clinical and social outcomes for long-stay psychiatric inpatients discharged to the community.

14 Leff J, O'Driscoll C, Dayson D, Wills W, Anderson J. The TAPS Project. 5: The structure of social-network data obtained from long-stay patients. 5: The structure of social-network
Brf Psychiatr 1990;157:848-52

15 Herxheimer A, Collier J, eds. Drug and Therapeutic Bulletin. 1991;29:41-2. 